\title{
Diabetes Converts Arterial Regulation by Perivascular Adipose Tissue From Relaxation Into $\mathrm{H}_{2} \mathrm{O}_{2}$-Mediated Contraction
}

\author{
R. EMILOVA ${ }^{1 *}$, D. Z. DIMITROVA ${ }^{2 *}$, M. MLADENOV ${ }^{3}$, N. HADZI-PETRUSHEV ${ }^{3}$, \\ T. DANEVA ${ }^{4}$, P. PADESHKI ${ }^{5}$, R. SCHUBERT ${ }^{6}$, M. CHICHOVA ${ }^{7}$, L. LUBOMIROV ${ }^{8}$, \\ D. SIMEONOVSKA-NIKOLOVA ${ }^{7}$, H. GAGOV ${ }^{7}$ \\ ${ }^{*}$ R.E. and D.Z.D. contributed equally to this work as first authors.
}

${ }^{1}$ Cytogenetics Laboratory, University Paediatric Hospital, Medical University, Sofia, Bulgaria, ${ }^{2}$ Bulgarian Academy of Sciences, Institute of Biophysics and Biomedical Engineering, Sofia, Bulgaria, ${ }^{3}$ University of Skopje Sts. Cyril and Methodius, Faculty of Natural Sciences and Mathematics, Institute of Biology, Skopje, Macedonia, ${ }^{4}$ Bulgarian Academy of Sciences, Institute of Biology and Immunology of Reproduction, Sofia, Bulgaria, ${ }^{5}$ National Center of Infectious and Parasitic Diseases, Sofia, Bulgaria, ${ }^{6}$ Ruprecht-Karls-University Heidelberg, Medical Faculty Mannheim, Department of Cardiovascular Physiology, Mannheim, Germany, ${ }^{7}$ Sofia University St. Kliment Ohridski, Faculty of Biology, Sofia, Bulgaria, ${ }^{8}$ Institute of Vegetative Physiology, University of Cologne, Germany

Received March 15, 2015

Accepted April 1, 2016

On-line July 15, 2016

\section{Summary}

This study aims to reveal the reason for the increased force of 5-hydroxytryptamine-induced contraction of endotheliumdenuded skeletal muscle arteries of diabetic rats in the presence of perivascular adipose tissue (PVAT). Our data on rat gracilis arteries show that i) PVAT of skeletal muscle arteries of healthy and diabetic rats releases hydrogen peroxide $\left(\mathrm{H}_{2} \mathrm{O}_{2}\right)$, ii) higher concentrations of 5-hydroxytryptamine increase the production of $\mathrm{H}_{2} \mathrm{O}_{2}$ in PVAT; iii) an enhanced PVAT production of $\mathrm{H}_{2} \mathrm{O}_{2}$ is the main, if not the only, reason for the sensitization of arterial contraction to 5-hydroxytriptamine-induced contraction in diabetes and iv) endothelium antagonizes the effect of PVATderived $\mathrm{H}_{2} \mathrm{O}_{2}$.

\section{Key words}

Artery • Regulation • Reactive oxygen species • Adipose tissue • Serotonin

\section{Corresponding author}

H. Gagov, Faculty of Biology, Sofia University St. Kliment Ohridski, 8 Dragan Tsankov Blvd, 1164 Sofia, Bulgaria. E-mail: hgagov@abv.bg

\section{Introduction}

Perivascular adipose tissue (PVAT) encloses most of the systemic blood vessels (Cinti 2002). It has been demonstrated that PVAT releases many paracrine vasodilators and vasoconstrictors (Gollasch 2012, Orinovo 2015). PVAT also regulates smooth muscle cell proliferation and migration, trans-endothelial migration of monocytes, apoptosis of neutrophils, the inflammatory reaction of pro- or anti-inflammatory adipokines and cytokines (Rajsheker et al. 2010), pro- and anti-oxidant mechanisms (Gil-Ortega et al. 2014) and others.

Hydrogen sulfide $\left(\mathrm{H}_{2} \mathrm{~S}\right)$ has a significant impact on the predominantly relaxing influence of PVAT on arteries isolated from healthy animals, including rat gracilis artery (a. gracilis) (Zavaritskaya et al. 2013, Schleifenbaum et al. 2010). Thus, $\mathrm{H}_{2} \mathrm{~S}$ seems to be an important, if not the main adipocyte-derived relaxing factor (ADRF), the physiological activator of voltage gated potassium channels of the $\mathrm{K}_{\mathrm{v} 7}$ (KCNQ channels) in arteries (Gollasch 2012, Zavaritskaya et al. 2013, Schleifenbaum et al. 2010, Köhn et al. 2012). The 
vasodilatory regulation by PVAT is lost or reversed to constriction by diabetes (Emilova et al. 2015, Houben et al. 2012), obesity, metabolic syndrome (Greenstein et al. 2009), and cardiovascular disease (Houben et al. 2012). It is obvious that pathologic conditions attenuate the PVAT-evoked vasodilatory regulation of vascular tone, but the mediator or mediators of these PVAT effects, in particular the PVAT-dependent constriction in diabetes, are still to be investigated (Emilova et al. 2015, Houben et al. 2012).

Diabetes influences negatively the entire vascular wall to a different extent - mostly the endothelium (Greenstein et al. 2009), and to a lesser extent - the smooth muscle layer (Ding and Triggle 2010), while changes in sympathetic innervation vary from minor in short-term diabetes (Damon 2011) to severe neuroaxonal dystrophy, an axonopathy of terminal axons and synapses in long-term type 1 diabetes (Schmidt et al. 2004). Reactive oxygen species (ROS) participate in diabetic vascular dysfunction (Nicolls et al. 2007), in particular in the impaired regulation of arterial tone (Erdei et al. 2007) and in agonist-induced contractions (Kobayashi and Kamata 2002). Hydrogen peroxide $\left(\mathrm{H}_{2} \mathrm{O}_{2}\right)$ is a relatively stable, plasma membrane permeable, and a non-radical form of ROS possessing moderate oxidant activity (Rodriguez-Martinez et al. 1998). Several studies propose an important role of $\mathrm{H}_{2} \mathrm{O}_{2}$ in the regulation of arterial responses - that of both constriction and dilation - in physiological and pathophysiological conditions (Erdei et al. 2007). In rats with STZ-induced diabetes, the elevated production of $\mathrm{H}_{2} \mathrm{O}_{2}$ mediates endothelium-dependent contractions of the femoral artery (Shi et al. 2007), which leads to a selective loss of endothelium-dependent vasodilation of the thoracic aorta (Kobayashi and Kamata 2002) and modulates angiotensin-II-induced contractions of mesenteric arteries (Chin et al. 2007). Therefore, the aim of our study is to test the hypothesis that $\mathrm{H}_{2} \mathrm{O}_{2}$ is the mediator of the reversed PVAT regulation of skeletal muscle artery contraction in STZ-treated diabetic rats.

\section{Methods}

All experimental procedures were conducted in accordance with the Guiding Principles for Care and Use of Laboratory Animals approved by the Bulgarian Center for Bioethics and are in accordance with the International Guiding Principles for Biomedical Research Involving Animals. In this study, native and endothelium-denuded ring preparations of rat a. gracilis with or without PVAT were used. The regulatory role of PVAT was explored under three different conditions - in $5.5 \mathrm{mM}$ glucosecontaining physiological salt solution (PSS, healthy rats, control conditions), in $20 \mathrm{mM}$ glucose-PSS (healthy rats, supra-physiological glucose concentration) and in the same $20 \mathrm{mM}$ glucose-PSS for artery preparations from diabetic rats.

Diabetes was induced in male Wistar rats (8-10 weeks old, supplied by ERBOJ-Slivnitza, Bulgaria) by a single intraperitoneal injection of STZ $(80 \mathrm{mg} / \mathrm{kg}$ body weight). A STZ application solution based on a citrate buffer $(\mathrm{pH}=4.5)$ was prepared immediately prior to treatment. Blood glucose levels were measured by a glucometer (Rapid Diagnostic PVT Ltd., Delhi, India) at the end of the first week after the induction of diabetes and again just prior to the experiments. Animals with blood glucose levels above $20 \mathrm{mM}(360 \mathrm{mg} / \mathrm{dl})$ were considered diabetic.

Male rats were used six to nine weeks after STZ treatment. The gracilis arteries were dissected and transferred to cold PSS $\left(4{ }^{\circ} \mathrm{C}\right)$. The PVAT and connective tissue of these preparations were either removed, or left intact. Otherwise, all artery preparations were treated according to the same protocol. The effect of PVAT signaling is directed to the artery smooth muscle layer (Emilova et al. 2015). For this reason, we used mainly endothelium-denuded a. gracilis preparations. The presence or absence of the endothelium was confirmed by the appearance or lack of relaxation in $10^{-5} \mathrm{M}$ acetylcholine of $60 \mathrm{mM}$ KCl-contracted arteries. Isometric vessel contractions were measured with a Dual Vessel Myograph (DMT 410M, Aarhus, Denmark). The organ bath was filled with PSS containing (in $\mathrm{mM}$ ): $119 \mathrm{NaCl}, 4.7 \mathrm{KCl}, 1.2 \mathrm{KH}_{2} \mathrm{PO}_{4}, 25 \mathrm{NaHCO}_{3}$, $1.2 \mathrm{Mg}_{2} \mathrm{SO}_{4}, 1.6 \mathrm{CaCl}_{2}, 5.5$ or 20 glucose. The bath solution was continuously exposed to a gas mixture of $95 \% \mathrm{O}_{2}$ and $5 \% \mathrm{CO}_{2}$, and kept at $37^{\circ} \mathrm{C}, \mathrm{pH}=7.4$. Arterial contractions are expressed as the percentage of the steady-state tension $(100 \%)$ obtained with isotonic PSS containing $60 \mathrm{mM} \mathrm{KCl}$, where $54 \mathrm{mM}$ of $\mathrm{NaCl}$ were replaced with $54 \mathrm{mM} \mathrm{KCl}$. Increasing concentrations of 5-hydroxytryptamine (5-HT) from $10^{-10}$ to $10^{-5} \mathrm{M}$ were applied to induce gradual constriction of the circular $2 \mathrm{~mm}$ long artery rings. In experiments with catalase, three cumulative applications of 5-HT $\left(10^{-10}-10^{-5} \mathrm{M}\right)$ were used. First and third 5-HT applications were control measurements of artery tensions in catalase-free PSS. 
Table 1. Effect of PVAT on 5-HT-induced contractions of a. gracilis of healthy and diabetic rats, expressed as \% of contractions in $60 \mathrm{mM} \mathrm{KCl}$.

\begin{tabular}{lccccccc}
\hline Group / log[5-HT] (M) & $\mathbf{- 9}$ & $\mathbf{- 8}$ & $\mathbf{- 7}$ & $\mathbf{- 6}$ & $\mathbf{- 5}$ & $\mathbf{n}$ & $\mathbf{N}$ \\
\hline $5.5 \mathrm{mM}$ glucose $+P V A T$ & $1.7 \pm 0.2$ & $3.7 \pm 1.0^{* *}$ & $51.6 \pm 3.0^{* * *}$ & $108.0 \pm 3.7^{*}$ & $131.6 \pm 3.1$ & 28 & 16 \\
$5.5 \mathrm{mM}$ glucose-PVAT & $2.2 \pm 0.4$ & $33.7 \pm 2.4^{*}$ & $97.9 \pm 3.6$ & $130.6 \pm 3.2$ & $136.2 \pm 3.5$ & 27 & 15 \\
$20 \mathrm{mM}$ glucose $+P V A T$ & $1.0 \pm 0.3$ & $6.6 \pm 1.1^{*}$ & $47.3 \pm 2.7 * *$ & $110.6 \pm 2.6^{*}$ & $138.6 \pm 2.1$ & 19 & 11 \\
$20 \mathrm{mM}$ glucose-PVAT & $1.1 \pm 0.3$ & $27.4 \pm 2.6$ & $88.8 \pm 5.3$ & $125.8 \pm 3.2$ & $137.8 \pm 3.4$ & 21 & 12 \\
STZ+PVAT & $2.2 \pm 0.6$ & $16.6 \pm 4.3$ & $105.3 \pm 8.0$ & $171.6 \pm 6.7^{*}$ & $189.4 \pm 7.6^{* *}$ & 8 & 5 \\
STZ-PVAT & $1.7 \pm 0.3$ & $24.8 \pm 6.8$ & $121.2 \pm 6.5$ & $149.2 \pm 6.8$ & $157.3 \pm 9.9$ & 9 & 5 \\
\hline
\end{tabular}

PVAT-containing versus PVAT-free preparations are compared. Values are expressed as mean $\pm \mathrm{SEM}, * \mathrm{p}<0.05, * * \mathrm{p}<0.01$, *** $\mathrm{p}<0.001, \mathrm{n}=$ number of experiments and $\mathrm{N}=$ number of animals per group. Data are presented as mean $\pm \mathrm{SEM}$. $\mathrm{E}_{\max }$ values for all conditions are not different compared to the contraction induced by a single application of $10^{-5} \mathrm{M} 5-\mathrm{HT}$.

Before starting the second 5-HT addition, the vascular rings were incubated with catalase or vehicle $\left(\mathrm{H}_{2} \mathrm{O}\right)$ for $15 \mathrm{~min}$. Forces of contractions are presented as a percentage of $60 \mathrm{mM} \mathrm{KCl-elicited} \mathrm{tensions.} \mathrm{Data}$ obtained in the presence of catalase were compared with these from the first 5-HT application. All drugs were added into the organ bath. The salts and drugs were obtained from Sigma-Aldrich (St. Louis, MO, USA).

The $\mathrm{H}_{2} \mathrm{O}_{2}$ release was determined according to the method of Pick and Keisari (1980). In brief, to measure the effect of 5-HT at concentrations of $10^{-7} \mathrm{M}$ or $10^{-5} \mathrm{M}$ on $\mathrm{H}_{2} \mathrm{O}_{2}$ release, PVAT was dissected from the region of the femoral artery (a. femoralis) including the a. gracilis from control and diabetic animals and incubated with PSS, containing phenol red and horseradish peroxidase (PRS), for $30 \mathrm{~min}$ at $37{ }^{\circ} \mathrm{C}$. At the end of the incubation, the supernatants were centrifuged for $5 \mathrm{~min}$ at $200 \mathrm{~g}$, at $4{ }^{\circ} \mathrm{C}$. $\mathrm{NaOH}(1 \mathrm{M})$ was then added and the extinction of the samples was determined at $600 \mathrm{~nm}$ against reference samples containing PRS and $\mathrm{NaOH}$ without PVAT. The $\mathrm{H}_{2} \mathrm{O}_{2}$ content was calculated using a standard curve, with the same batch and concentration of PRS and $\mathrm{NaOH}$ to which $\mathrm{H}_{2} \mathrm{O}_{2}$ was added at known final concentrations. All experiments were performed in duplicate and the results were expressed as $\mathrm{nM} \mathrm{H}_{2} \mathrm{O}_{2} / \mathrm{min} / \mathrm{g}$ PVAT.

The data obtained from the isometric contraction measurements were analysed using the statistical software SPSS 16.0. Usually the number of rats $(\mathrm{N})$ is half the number of experiments (n). In some series, the $\mathrm{N} / \mathrm{n}$ ratio is higher due to failed measurements that required additional experiments with vessels from other animals. The results are given as means \pm SEM from six or more separate experiments. The statistical significance was determined using the Student t-test for unpaired samples to assess the significance between two groups. For $\mathrm{H}_{2} \mathrm{O}_{2}$ assay data, one-way ANOVA Kruskal-Wallis tests, followed by Dunn's multiple comparison post hoc tests were performed. Differences were considered significant when $\mathrm{p}<0.05$. GraphPad Prism6 was used to calculate $\mathrm{pEC}_{50}$ of 5-HT contractions.

\section{Results}

At the time of treatment the body weights of control and STZ-treated rats were comparable $(173 \pm 9 \mathrm{~g}$ and $178 \pm 6 \mathrm{~g}$ ). Two weeks after STZ treatment, PVAT was transformed from its native, multiple pearl-like structures into a thin, brown-colored tunic that seemed functionally inactive because its presence did not affect the 5-HT-induced contraction in diabetic a. gracilis (data not shown). After about 4 weeks, the normal appearance of PVAT was recovered and this was the reason to wait for more than a month after STZ treatment before starting the experiments with diabetic animals. Six to nine weeks after STZ-treatment the rats gained weight that was significantly lower $(228 \pm 9 \mathrm{~g}, \quad \mathrm{p}<0.05)$ compared to healthy controls $(289 \pm 12 \mathrm{~g})$. STZ-diabetic animals developed polyuria and a specific appearance of their fur - separate bristle hairs.

Data for PVAT relaxations (significant at $10^{-8}$, $10^{-7}$ and $10^{-6} \mathrm{M}$ ) of control a. gracilis and PVATmediated contractions (significant at $10^{-6}$ and $10^{-5} \mathrm{M}$ ) of diabetic vessels are presented in Table 1. The presence of PVAT did not change $\mathrm{E}_{\max }$ of control artery preparations, estimated as the force of contractions obtained in the presence of $10^{-5} \mathrm{M}$ 5-HT, while $\mathrm{E}_{\max }$ significantly increased in PVAT-containing diabetic vessels. 
Figure 1 presents data on the effect of catalase $(1,000 \mathrm{U} / \mathrm{ml})$ on 5 -HT-induced contractions obtained from endothelium-denuded a. gracilis preparations without PVAT from healthy rats in the presence of physiological (Fig. 1a) and supra-physiological glucose concentrations (Fig. 1b), and from diabetic rats (Fig. 1c). Artery preparations from animals with diabetes
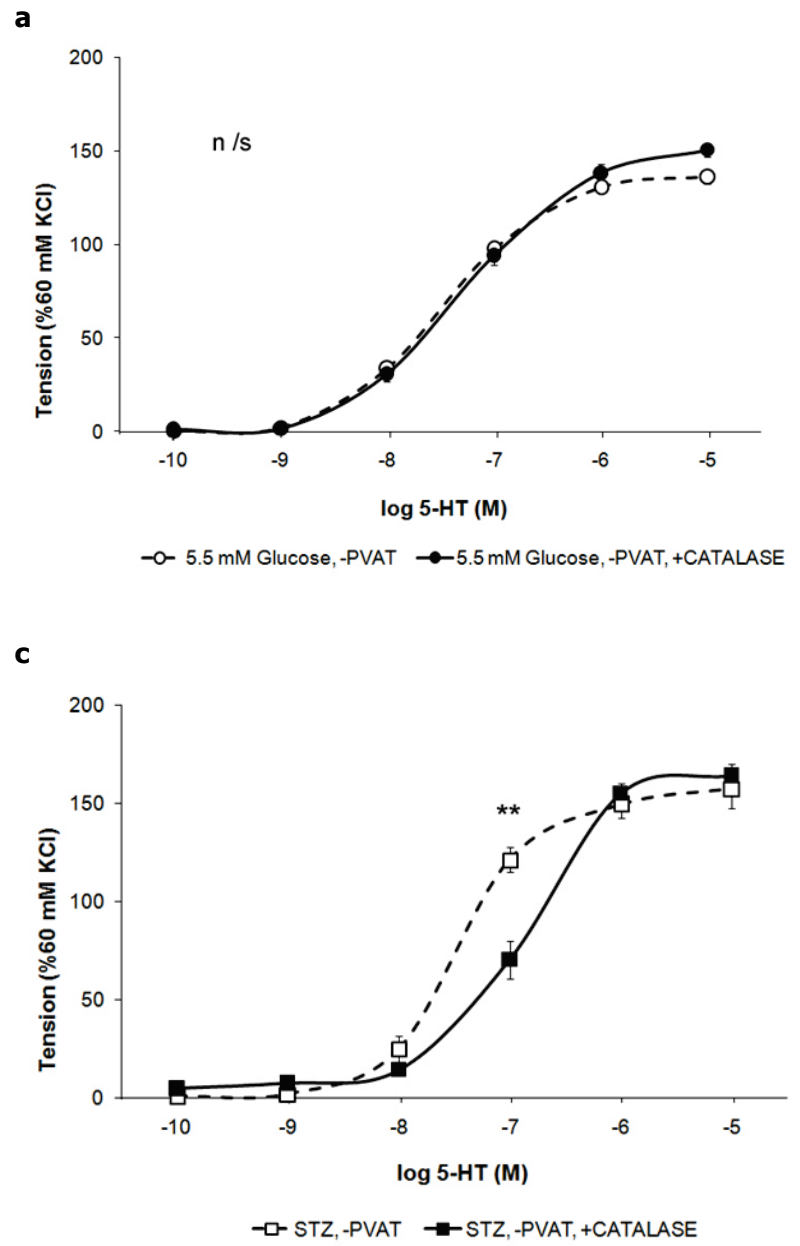

developed weaker contractions at $10^{-7} \mathrm{M} 5$-HT in the presence of catalase compared to its absence (Fig. 1c, $\mathrm{p}<0.01)$. In the presence of catalase, 5-HT-induced contractions of vessels from healthy animals kept in normal and supra-physiological glucose concentrations, and from diabetic rats were the same (Fig. 1d).

b

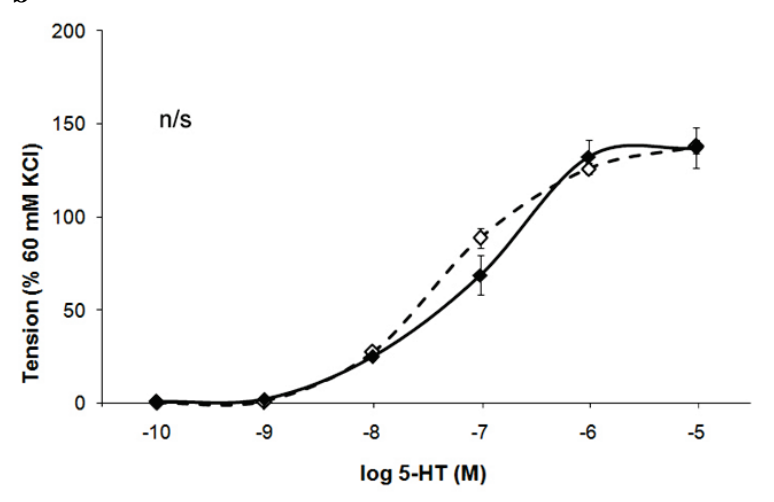

$\rightarrow 20 \mathrm{mM}$ Glucose, -PVAT $\rightarrow 20 \mathrm{mM}$ Glucose, -PVAT, +CATALASE

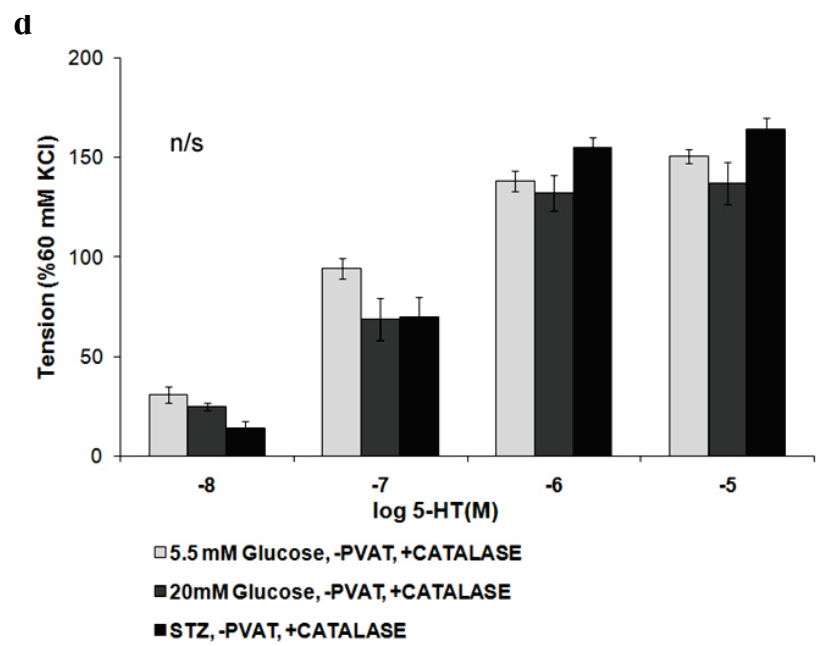

Fig. 1. Effect of catalase on $5-H T$ induced contractions of PVAT-free a. gracilis preparations in physiological $(a, n=6 ; p>0.05$, nonsignificant $(n / s)$ ) and supra-physiological glucose concentrations $(\mathbf{b}, n=6 ; p>0.05, n / s)$ as well as in diabetic conditions (c, $n=6$; ** p < 0.01). Open symbols - absence of catalase; closed symbols - presence of $1,000 \mathrm{U} / \mathrm{ml}$ catalase. d) Normalized contractions of PVAT-free a. gracilis preparations in the presence of catalase at different $5-H T$ concentrations $(n=6 ; p>0.05, n / s)$.

In the presence of PVAT, the addition of catalase did not affect the concentration dependence of 5-HT-induced force of contraction of endotheliumdenuded preparations from healthy animals, neither in physiological nor in supra-physiological glucose concentrations (Fig. 2a, b). In contrast, in diabetic a. gracilis rings with PVAT, the presence of catalase strongly decreased the force of contraction at all tested concentrations of 5-HT above $10^{-8} \mathrm{M}$ (Fig. 2c). Thus, the catalase-induced difference in the force of contraction was much more pronounced in PVAT-containing diabetic arteries (Fig. 2c) compared to PVAT-free ones. In the same artery preparations with preserved endothelium this effect was not significant (Fig. 2c, triangles). Catalase also decreased significantly the contractions of PVATfree preparations from STZ-treated rats but only at $10^{-7} \mathrm{M}$ 5-HT (121.2 $\pm 6.5 \%$ for PVAT-free versus $70.1 \pm 9.7 \%$ for PVAT-controls, $\mathrm{p}<0.01$, Fig 1c). This increase of the force of contraction of PVAT-free vessels probably depends on $\mathrm{H}_{2} \mathrm{O}_{2}$ produced in the smooth muscle layer of 
a. gracilis. The presence of catalase eliminated the difference in the force of contractions of preparations from healthy and diabetic animals (Fig. 1d, 2d). In the absence of catalase, the calculated $\mathrm{pEC}_{50}$ of 5-HTinduced contractions in healthy a. gracilis preparations with PVAT incubated in $5.5 \mathrm{mM}$ or $20 \mathrm{mM}$ glucosecontaining PSS is lower in vessels with PVAT compared to PVAT-free vessels (Table 2). On the other hand, $\mathrm{pEC}_{50}$

a

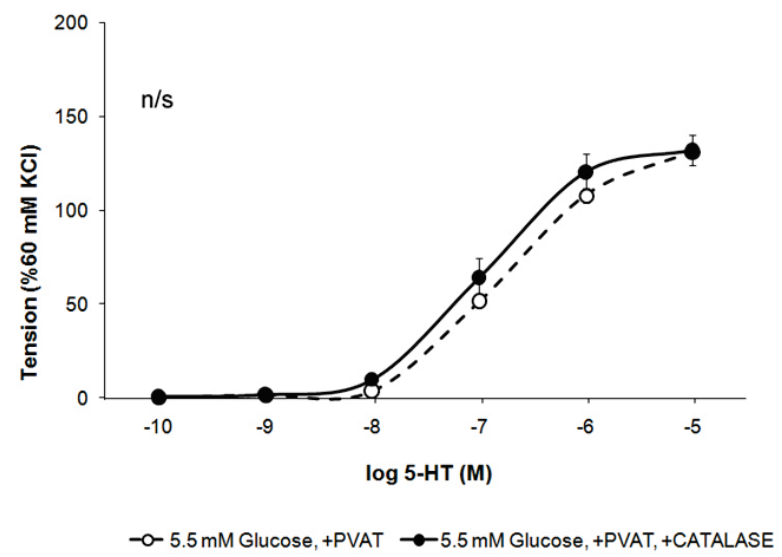

C

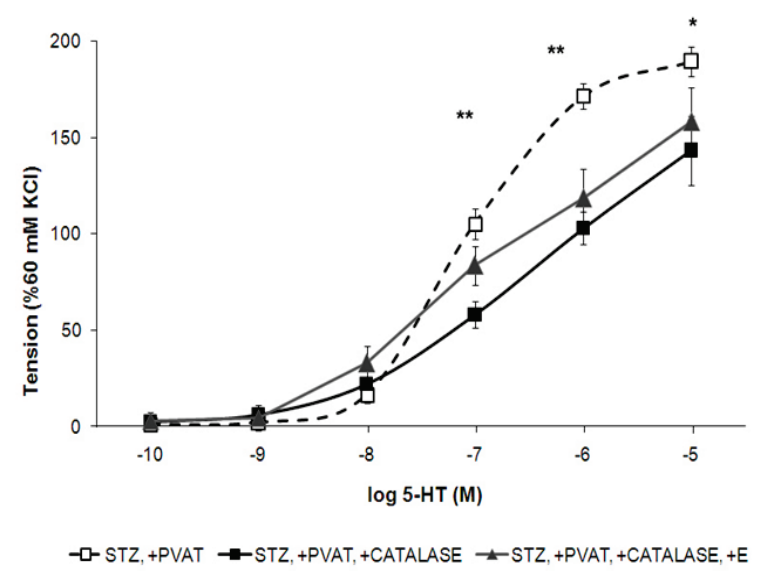

of 5-HT-induced contractions of diabetic vessels free of PVAT is not different from that of vessels with PVAT. The addition of catalase eliminates the difference of the $\mathrm{pEC}_{50}$ in supra-physiological glucose concentration. Catalase decreases the $\mathrm{pEC}_{50}$ of 5-HT-induced force of contractions of diabetic a. gracilis with or without PVAT. In the presence of PVAT, however, this effect was much more pronounced (Table 2, last row).

b

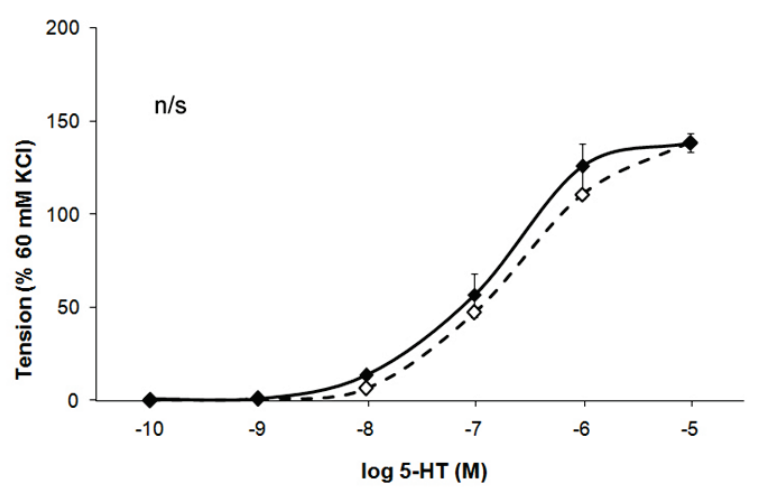

$\multimap 20 \mathrm{mM}$ Glucose, +PVAT $\rightarrow 20 \mathrm{mM}$ Glucose, +PVAT, +CATALASE

d

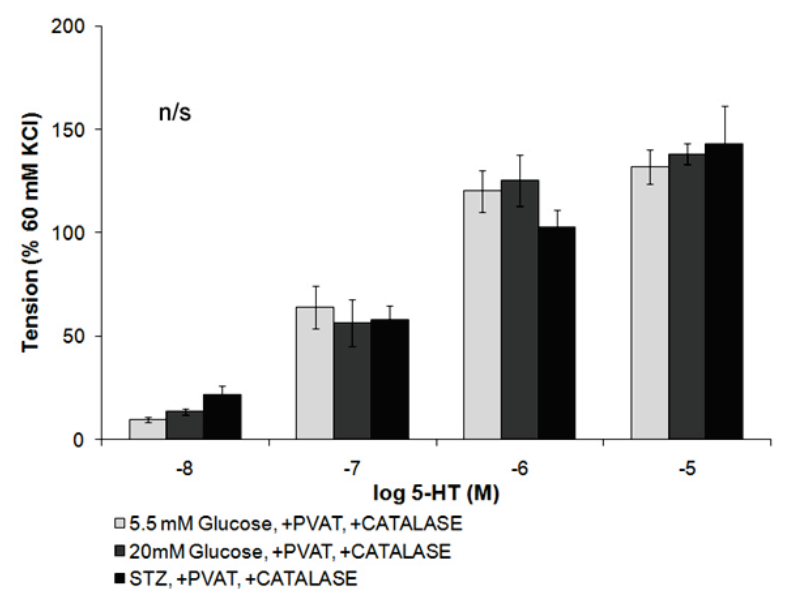

Fig. 2. Effect of catalase on $5-H T$ induced contractions of PVAT-containing a. gracilis preparations in physiological $(\mathbf{a}, n=6 ; p>0.05$, $\mathrm{n} / \mathrm{s})$ and supra-physiological glucose concentrations $(\mathbf{b}, \mathrm{n}=6 ; \mathrm{p}>0.05, \mathrm{n} / \mathrm{s})$ as well as in diabetic conditions $(\mathbf{c}, \mathrm{n}=6 ; * * \mathrm{p}<0.01)$. Open symbols - absence of catalase; closed symbols - presence of $1,000 \mathrm{U} / \mathrm{ml}$ catalase. Triangles in c) illustrate the effect of preserved endothelium on 5-HT induced contractions of PVAT-containing preparations. d) Normalized contractions PVAT-containing a. gracilis preparations in the presence of catalase at different $5-\mathrm{HT}$ concentrations $(n=6 ; p>0.05)$.

The $\mathrm{H}_{2} \mathrm{O}_{2}$ production by PVAT in the presence of $10^{-7}$ or $10^{-5} \mathrm{M} 5$-HT was studied using PVAT isolated from the region of a. gracilis and a. femoralis of healthy and diabetic rats (Fig. 3a). Only the amount of PVAT of the a. gracilis area was very small; therefore, we also used PVAT from the adjacent a. femoralis. In healthy animals, the production of $\mathrm{H}_{2} \mathrm{O}_{2}$ by PVAT was higher at $10^{-5} \mathrm{M} 5$-HT compared to $10^{-7} \mathrm{M} 5$-HT $(\mathrm{p}<0.01)$. PVAT isolated from vessels of diabetic rats also released more $\mathrm{H}_{2} \mathrm{O}_{2}$ at $10^{-5} \mathrm{M}$ 5-HT compared to $10^{-7} \mathrm{M}$ 5-HT $(\mathrm{p}<0.05)$. The amount of $\mathrm{H}_{2} \mathrm{O}_{2}$ released from diabetic PVAT was larger compared to that of healthy PVAT at both 5-HT concentrations studied (for both 5-HT concentrations, $\mathrm{p}<0.001$ ). The observed effect of catalase (Fig. 2c) suggested an involvement of $\mathrm{H}_{2} \mathrm{O}_{2}$ in the contractionenhancing effect of PVAT in diabetic animals. Therefore, 
we tested the influence of externally applied $\mathrm{H}_{2} \mathrm{O}_{2}$ on vessel preparations without PVAT from healthy and diabetic rats. In the presence of $60 \mathrm{mM} \mathrm{KCl-containing}$ PSS, which was used to induce a moderate contraction of the a. gracilis, the subsequent addition of increasing concentrations of $\mathrm{H}_{2} \mathrm{O}_{2}$ from $1 * 10^{-6} \mathrm{M}$ to $33^{*} 10^{-6} \mathrm{M}$ gradually enhanced their force of contraction (Fig. 3b, $\mathrm{p}<0.001$ and $\mathrm{n}=6$ for time control versus $\mathrm{H}_{2} \mathrm{O}_{2}$ in preparations from healthy animals and $\mathrm{p}<0.01, \mathrm{n}=6$ for time control versus $\mathrm{H}_{2} \mathrm{O}_{2}$ in preparations from diabetic rats). This effect was reversed into a decreased force of contraction at concentrations of $10^{-4} \mathrm{M}$ and $3.3^{*} 10^{-4} \mathrm{M}$ $\mathrm{H}_{2} \mathrm{O}_{2}$ (Fig. 3b, $\mathrm{p}<0.001$ ). Thus, a small concentration step from $33 \mu \mathrm{M}$ to $100 \mu \mathrm{M}$ is sufficient to change the effect of $\mathrm{H}_{2} \mathrm{O}_{2}$ dramatically. Importantly, the relaxing potency of $\mathrm{H}_{2} \mathrm{O}_{2}$ above $33 * 10^{-6} \mathrm{M}$ was smaller in diabetic as compared to healthy arteries $(\mathrm{p}<0.001, \mathrm{n}=6)$, which suggests a suppression of relaxing $\mathrm{H}_{2} \mathrm{O}_{2}$ signaling in diabetic arteries.

Table 2. $\mathrm{pEC}_{50}$ of 5-HT-induced contractions of rat a. gracilis with or without PVAT and catalase.

\begin{tabular}{|c|c|c|c|c|c|}
\hline Series & $\mathrm{pEC}_{50}$ for 5-HT & -PVAT & + PVAT & $\mathbf{n}$ & $\mathbf{N}$ \\
\hline $5.5 \mathrm{mM}$ glucose & $\mathrm{pEC}_{50}$ & $7.47 \pm 0.12$ & $6.73 \pm 0.15^{* * *}$ & 10 & 5 \\
\hline $5.5 \mathrm{mM}$ glucose & $\mathrm{pEC}_{50}+$ catalase & $7.15 \pm 0.11$ & $6.90 \pm 0.11 * *$ & 10 & 5 \\
\hline $20 \mathrm{mM}$ glucose & $\mathrm{pEC}_{50}$ & $7.26 \pm 0.08$ & $6.69 \pm 0.11 * * *$ & 6 & 3 \\
\hline $20 \mathrm{mM}$ glucose & $\mathrm{pEC}_{50}+$ catalase & $6.93 \pm 0.11$ & $6.88 \pm 0.11 \mathrm{n} / \mathrm{s}$ & 6 & 3 \\
\hline STZ-treated & $\mathrm{pEC}_{50}$ & $7.37 \pm 0.11$ & $7.20 \pm 0.12 \mathrm{n} / \mathrm{s}$ & 6 & 3 \\
\hline STZ-treated & $\mathrm{pEC}_{50}+$ catalase & $6.88 \pm 0.12$ & $6.43 \pm 0.12 * *$ & 6 & 3 \\
\hline
\end{tabular}

PVAT-containing versus PVAT-free preparations are compared. Values are expressed as mean $\pm \mathrm{SEM}, * * \mathrm{p}<0.01, * * * \mathrm{p}<0.001$, $\mathrm{n}=$ number of experiments and $\mathrm{N}=$ number of animals per group.

a

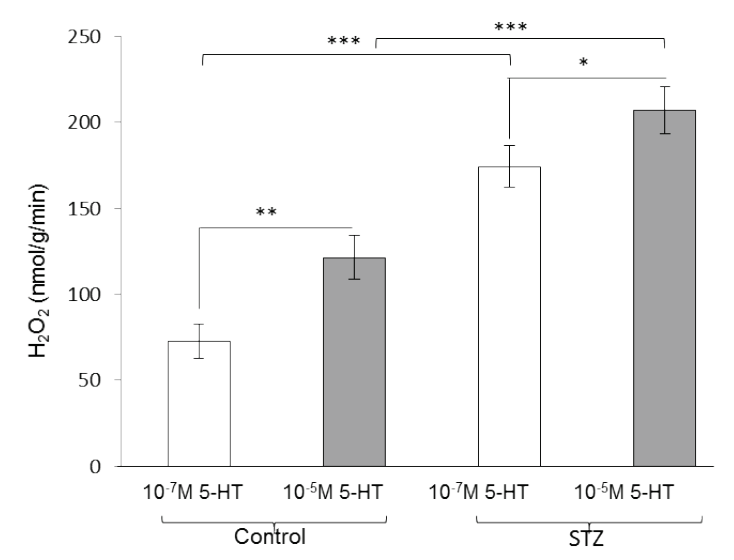

c

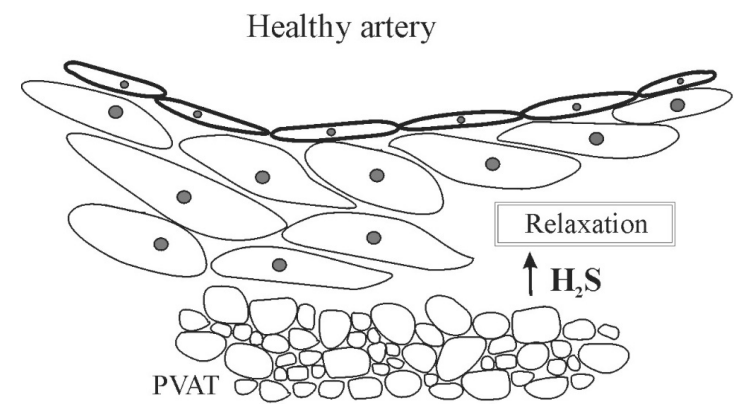

b

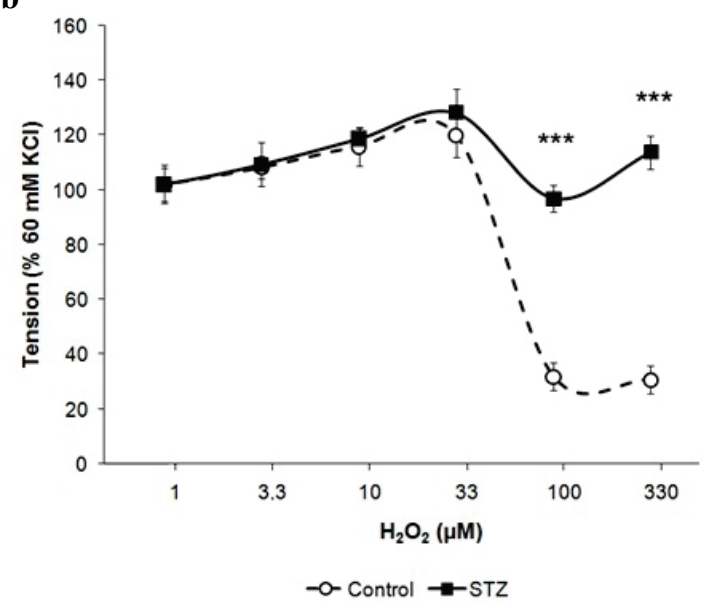

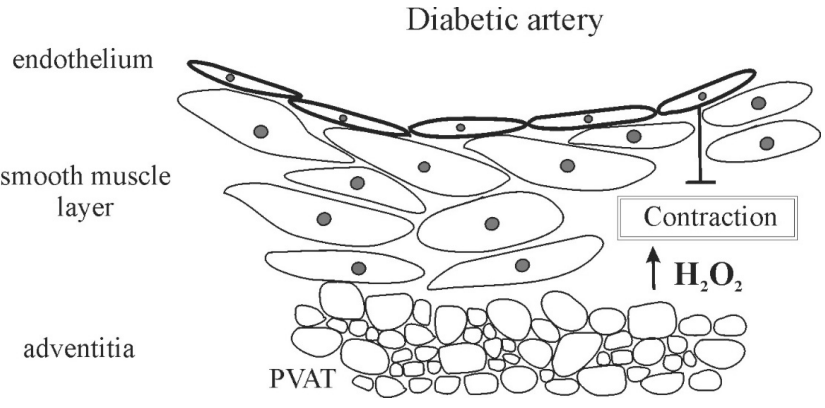

Fig. 3. $\mathrm{H}_{2} \mathrm{O}_{2}$ production by PVAT in the presence of $10^{-7} \mathrm{M} 5-\mathrm{HT}$ (blank bars) or $10^{-5} \mathrm{M} 5-\mathrm{HT}$ (shaded bars) from healthy (Control) and diabetic (STZ) rats $\left(\mathbf{a}, \mathrm{n}=6\right.$; $* \mathrm{p}<0.05$, ** $\mathrm{p}<0.01$ ). Effect of $\mathrm{H}_{2} \mathrm{O}_{2}$ on contractions of a. gracilis preparations induced by 60 mM $\mathrm{KCl}-$ containing PSS from healthy (open circles) and diabetic (closed squares) rats (b, $\mathrm{n}=6$; $* * * \mathrm{p}<0.001$ ). Representative diagram with common mediators of PVAT participating in a. gracilis regulation in health and diabetes (c). 


\section{Discussion}

The novel findings of this study are: i) PVAT of skeletal muscle arteries of healthy and diabetic rats releases $\mathrm{H}_{2} \mathrm{O}_{2}$, ii) 5-HT increases the production of $\mathrm{H}_{2} \mathrm{O}_{2}$ in PVAT and iii) an enhanced $\mathrm{H}_{2} \mathrm{O}_{2}$ formation by PVAT is the main, if not the only, reason for the sensitization of a. gracilis to 5-HT in contractions.

A. gracilis preparations with PVAT from diabetic rats contract more strongly in the presence of moderate and high concentrations of 5-HT compared to those from healthy animals. This finding could be explained with several mechanisms - a smaller release of dilating mediator from PVAT, which most probably is $\mathrm{H}_{2} \mathrm{~S}$ (Zavaritskaya et al. 2013, Emilova et al. 2013), an enhanced vasoconstrictor release from PVAT, or both of them in vessels from diabetic animals. The first possibility - a loss or a vast decrease of PVAT-derived $\mathrm{H}_{2} \mathrm{~S}$ as the main reason for the observed phenomenon was not experimentally supported. The addition of DL-propargyl glycine, a selective inhibitor of cystathionine gamma-lyase, the main producer of $\mathrm{H}_{2} \mathrm{~S}$ in vascular walls, decreased contractions of a. gracilis preparations from diabetic rats in the presence of moderate and higher 5-HT concentrations (Emilova et al. 2015). Thus, the data suggest that a contractile mediator is responsible for the observed PVAT-dependent sensitization of diabetic a. gracilis contractions.

The relation of contractions and $\mathrm{H}_{2} \mathrm{~S}$ production in PVAT of diabetic a. gracilis (Emilova et al. 2015) and the intrinsic imbalance between pro- and anti-oxidant mechanisms (Gil-Ortega et al. 2014) leading to oxidative stress in diabetes (Nicolls et al. 2007) suggest that PVAT may release $\mathrm{H}_{2} \mathrm{O}_{2}$ as a vasoconstrictor. $\mathrm{H}_{2} \mathrm{~S}$ can influence the bio-availability of $\mathrm{H}_{2} \mathrm{O}_{2} \cdot \mathrm{H}_{2} \mathrm{~S}$ inhibits $\mathrm{H}_{2} \mathrm{O}_{2}$-mediated mitochondrial dysfunction by increasing the expression levels of antioxidant enzymes (Wen et al. 2013, Kimura 2014), by recovering glutathione level decreased by oxidative stress, by decreasing $\mathrm{Ca}^{2+}$ influx and by a ROS scavenging effect (Kimura 2014). The participation of adventitial $\mathrm{H}_{2} \mathrm{O}_{2}$ in vasoconstriction was tested using catalase. Catalase converts $\mathrm{H}_{2} \mathrm{O}_{2}$ into water and $\mathrm{O}_{2}$, and thus eliminates the paracrine effects of $\mathrm{H}_{2} \mathrm{O}_{2}$. In the presence of catalase 5-HT-induced contractions of PVAT-containing artery preparations from diabetic rats are significantly suppressed if compared to the same reactions in enzyme-free conditions. Catalase eliminates the difference of concentration-dependent 5-HT contractions of PVAT-containing a. gracilis preparations between diabetic and healthy rats. The presence of catalase decreases the $\mathrm{pEC}_{50}$ of 5-HT-induced contractions in both PVAT-free and PVAT-containing vessels from healthy animals. Additionally, catalase creates a significant difference between these two groups due to a moderate decrease of $\mathrm{pEC}_{50}$ in PVAT-containing preparations and a vast decrease of $\mathrm{pEC}_{50}$ in PVAT-free vessels. The effects of catalase on PVAT-free arteries suggest that some $\mathrm{H}_{2} \mathrm{O}_{2}$ could be produced in the smooth muscle layer of a. gracilis. The vigorous decrease of $\mathrm{E}_{\max }$ and $\mathrm{pEC}_{50}$ in PVAT-containing preparations caused by catalase suggests that PVAT dominates as a producer of the mediator sensitizing the diabetic vascular bed to 5-HT. Different $\mathrm{pEC}_{50}$ values of diabetic vessels with PVAT and without PVAT, both kept in catalasecontaining PSS, suggest the release of a vasodilator from PVAT. Its physiological influence, however, is concealed by $\mathrm{H}_{2} \mathrm{O}_{2}$.

This hypothesis for the important role of PVATderived $\mathrm{H}_{2} \mathrm{O}_{2}$ as a signal molecule in diabetes is supported by the previously established increased activity of NADPH oxidases in vascular walls (which are membrane-bound enzymes generating $\mathrm{H}_{2} \mathrm{O}_{2}$ in hypoxia, atherosclerosis, vascular injury and experimental diabetes), as well as by many pro- and anti-inflammatory factors, hormones and other mediators (Lassègue et al. 2012). NADPH oxidases and mitochondrial electron transport chains are the major routes for ROS production in a wide variety of cells, including adipocytes (Morrow 2003, Rolo and Palmeira 2006). Diabetes increases the formation of superoxide in mitochondria (Rolo and Palmeira 2006), which together with increased infiltration of inflammatory cells (Surmi and Hasti 2008) may cause the observed significant elevation of $\mathrm{H}_{2} \mathrm{O}_{2}$ production in PVAT.

Application of $\mathrm{H}_{2} \mathrm{O}_{2}$ leads to two opposite effects on rat a. gracilis: lower concentrations (1-33 $\mu \mathrm{M})$ induce gradual constrictions and concentrations above $33 \mu \mathrm{M}$ - considerable relaxations of diabetic and very large relaxations of control vessels. It is known that $\mathrm{H}_{2} \mathrm{O}_{2}$ signaling can either enhance or suppress vascular contractility. Thus, in endothelium-denuded arterioles from type 2 diabetic mice, exogenously administered $\mathrm{H}_{2} \mathrm{O}_{2}$ evokes constriction by stimulating the synthesis of thromboxane $\mathrm{A}_{2}$ in the vascular wall, while the same vessels from healthy animals dilate (Erdei et al. 2007). The increased production of constrictor prostaglandins in smooth muscle cells is mainly due to cytosolic phospholipase $\mathrm{A}_{2}$ activation and enhanced expression of 
cyclooxygenase-2 (Korbecki et al. 2013). In our experiments, the presence of catalase decreased the force of contraction of endothelium-denuded a. gracilis. This result suggests that PVAT and the smooth muscle layer release $\mathrm{H}_{2} \mathrm{O}_{2}$ in amounts that are below the transition concentration between $33 \mu \mathrm{M}$ and $100 \mu \mathrm{M}$ necessary to induce vasodilation. Similarly, Shi et al. (2007) report that application of $30 \mu \mathrm{M}$ exogenous $\mathrm{H}_{2} \mathrm{O}_{2}$ induces maximal contraction of endothelium-denuded femoral artery.

In conclusion, $\mathrm{H}_{2} \mathrm{O}_{2}$ is an important PVAT-derived vasoconstrictor of a. gracilis of rats with STZ-induced diabetes, which transforms the adventitial modulation of 5-HT-induced contractions from predominantly relaxing into constrictive. This regulation, however, is minimized by vascular endothelium. Thus, diabetes seems to convert the regulatory role of PVAT from protecting to pathogenic by inducing a proinflammatory phenotype of PVAT similarly to atherosclerosis and environmental factors such as a high-fat diet and tobacco smoke (Omar et al. 2014). Figure 3c presents a summary of PVAT common mediators and their paracrine regulations of skeletal muscle a. gracilis isolated from healthy (Zavaritskaya et al. 2013, Schleifenbaum et al. 2010, Emilova et al. 2015) and diabetic rats (this study).

\section{Conflict of Interest}

There is no conflict of interest.

\section{Acknowledgements}

This study was supported by Sofia University St. Kliment Ohridski, Sofia, Bulgaria, Projects 24/2013 and 20/2015, and by Ministry of Education and Science, Bulgaria, Project BG 051PO001-3.3.05-0001, No. 2-680/12.07.2013.

\section{References}

CHIN LC, ACHIKE FI, MUSTAFA MR: Hydrogen peroxide modulates angiotensin II-induced contraction of mesenteric arteries from streptozotocin-induced diabetic rats. Vascul Pharmacol 46: 223-228, 2007.

CINTI S: Adipocyte differentiation and transdifferentiation: plasticity of the adipose organ. $J$ Endocrinol Invest $\mathbf{2 5}$ : 823-835, 2002.

DAMON DH: Vascular-dependent effects of elevated glucose on postganglionic sympathetic neurons. Am J Physiol Heart Circ Physiol 300: H1386-H1392, 2011.

DEBRECZENI B, GARA E, VERESH Z, MARKI A, RACZ A, MATICS R, HAMAR J, KOLLER A: Hydrogen peroxide via thromboxane A2 receptors mediates myogenic response of small skeletal muscle veins in rats. Clin Hemorheol Microcirc 54: 393-407, 2013.

DING H, TRIGGLE CR: Endothelial dysfunction in diabetes: multiple targets for treatment. Pflugers Arch 459: 977-994, 2010.

EMILOVA R, DIMITROVA D, GEORGIEV V, DANEVA T, GAGOV H: Cystathionine gamma-lyase as a regulator of resistance artery contraction under normal and hyperglycemic conditions. Bulg J Agric Sci 19: 175-177, 2013.

EMILOVA R, DIMITROVA D, MLADENOV M, DANEVA T, SCHUBERT R, GAGOV H: Cystathionine gammalyase of perivascular adipose tissue with reversed regulatory effect in diabetic rat artery. Biotechnol Biotechnol Eq 29: 147-151, 2015.

ERDEI N, BAGI Z, EDES I, KALEY G, KOLLER A: $\mathrm{H}_{2} \mathrm{O}_{2}$ increases production of constrictor prostaglandins in smooth muscle leading to enhanced arteriolar tone in Type 2 diabetic mice. Am J Physiol Heart Circ Physiol 292: H649-H656, 2007.

GIL-ORTEGA M, CONDEZO-HOYOS L, GARCÍA-PRIETO CF, ARRIBAS SM, GONZÁLEZ MC, ARANGUEZ I, RUIZ-GAYO M, SOMOZA B, FERNÁNDEZ-ALFONSO MS: Imbalance between pro and anti-oxidant mechanisms in perivascular adipose tissue aggravates long-term high-fat diet-derived endothelial dysfunction. PLoS One 9: e95312, 2014.

GOLLASCH M: Vasodilator signals from perivascular adipose tissue. Br J Pharmacol 165: 633-642, 2012.

GREENSTEIN AS, KHAVANDI K, WITHERS SB, SONOYAMA K, CLANCY O, JEZIORSKA M, LAING I, YATES AP, PEMBERTON PW, MALIK RA, HEAGERTY AM: Local inflammation and hypoxia abolish the protective anticontractile properties of perivascular fat in obese patients. Circulation 119: 1661-1670, 2009. 
HOUBEN AJ, ERINGA EC, JONK AM, SERNE EH, SMULDERS YM, STEHOUWER CD: Perivascular fat and the microcirculation: relevance to insulin resistance, diabetes, and cardiovascular disease. Curr Cardiovasc Risk Rep 6: 80-90, 2012.

KIMURA H: Production and physiological effects of hydrogen sulfide. Antioxid Redox Signal 20: 783-793, 2014.

KOBAYASHI T, KAMATA K: Modulation by hydrogen peroxide of noradrenaline-induced contraction in aorta from streptozotocin-induced diabetic rat. Eur J Pharmacol 441: 83-89, 2002.

KORBECKI J, BARANOWSKA-BOSIACKA I, GUTOWSKA I, CHLUBEK D: The effect of reactive oxygen species on the synthesis of prostanoids from arachidonic acid. J Physiol Pharmacol 64: 409-421, 2013.

KÖHN C, SCHLEIFENBAUM J, SZIJÁRTÓ IA, MARKÓ L, DUBROVSKA G, HUANG Y, GOLLASCH M: Differential effects of cystathionine- $\gamma$-lyase-dependent vasodilatory $\mathrm{H} 2 \mathrm{~S}$ in periadventitial vasoregulation of rat and mouse aortas. PLoS One 7: e41951, 2012.

LASSÈGUE B, SAN MARTÍN A, GRIENDLING KK: Biochemistry, physiology, and pathophysiology of NADPH oxidases in the cardiovascular system. Circ Res 110: 1364-1390, 2012.

MORROW J: Is a oxidative stress a connection between obesity and atherosclerosis. Arterioscler Tromb Vasc Biol 23: 368-370, 2003.

OMAR A, CHATTERJEE TK, TANG Y, HUI DY, WEINTRAUB NL: Proinflammatory phenotype of perivascular adipocytes. Arterioscler Thromb Vasc Biol 34: 1631-1636, 2014.

ORIOWO MA: Perivascular adipose tissue, vascular reactivity and hypertension. Med Princ Pract 24 (Suppl 1): 29-37, 2015.

PICK E, KEISARI Y: A simple colorimetric method for the measurement of hydrogen peroxide produced by cells in culture. J Immunol Methods 38: 161-170, 1980.

RAJSHEKER S, MANKA D, BLOMKALNS AL, CHATTERJEE TK, STOLL LL, WEINTRAUB NL: Crosstalk between perivascular adipose tissue and blood vessels. Curr Opin Pharmacol 10: 191-196, 2010.

RODRIGUEZ-MARTINEZ MA, GARCIA-COHEN EC, BAENA AB, GONZALEZ R, SALAICES M, MARIN J: Contractile responses elicited by hydrogen peroxide in aorta from normotensive and hypertensive rats. Endothelial modulation and mechanism involved. Br J Pharmacol 125: 1329-1335, 1998.

ROLO AP, PALMEIRA CM: Diabetes and mitochondrial function: role of hyperglycemia and oxidative stress. Toxicol Appl Pharmacol 212: 167-178, 2006.

SCHLEIFENBAUM J, KÖHN C, VOBLOVA N, DUBROVSKA G, ZAVARIRSKAYA O, GLOE T, CREAN CS, LUFT FC, HUANG Y, SCHUBERT R, GOLLASCH M: Systemic peripheral artery relaxation by KCNQ channel openers and hydrogen sulfide. J Hypertens 28: 1875-1882, 2010.

SCHMIDT RE, DORSEY DA, BEAUDET LN, PARVIN CA, ZHANG W, SIMA AA: Experimental rat models of types 1 and 2 diabetes differ in sympathetic neuroaxonal dystrophy. J Neuropathol Exp Neurol 63: 450-460, 2004.

NICOLLS MR, HASKINS K, FLORES SC: Oxidant stress, immune dysregulation, and vascular function in type I diabetes. Antioxid Redox Signal 9: 879-889, 2007.

SEARLS YM, LOGANATHAN R, SMIRNOVA IV, STEHNO-BITTEL L: Intracellular Ca2+ regulating proteins in vascular smooth muscle cells are altered with type 1 diabetes due to the direct effects of hyperglycemia. Cardiovasc Diabetol 9: 8, 2010.

SHI Y, SO KF, MAN RY, VANHOUTTE PM: Oxygen-derived free radicals mediate endothelium-dependent contractions in femoral arteries of rats with streptozotocin-induced diabetes. Br J Pharmacol 152: 1033-1041, 2007.

SURMI BK, HASTY AH: Macrophage infiltration into adipose tissue: initiation, propagation and remodeling. Future Lipidol 3: 545-556, 2008.

WEN YD, WANG H, KHO SH, RINKIKO S, SHENG X, SHEN HM, ZHU YZ: Hydrogen sulfide protects HUVECs against hydrogen peroxide induced mitochondrial dysfunction and oxidative stress. PLoS One 8: e53147, 2013.

ZAVARITSKAYA O, ZHURAVLEVA N, SCHLEIFENBAUM J, GLOE T, DEVERMANN L, KLUGE R, MLADENOV M, FREY M, GAGOV H, FÉSÜS G, GOLLASCH M, SCHUBERT R: Role of KCNQ channels in skeletal muscle arteries and periadventitial vascular dysfunction. Hypertension 61: 151-159, 2013. 